Supporting Information

\title{
Unexpectedly Increased Particle Emissions from the Steel Industry Determined by Wet/Semidry/Dry Flue Gas Desulfurization Technologies
}

Xiang Ding ${ }^{\mathrm{a}}$, Qing $\mathrm{Li}^{\mathrm{a}} \mathrm{b}^{*}$, Di Wu${ }^{\mathrm{a}}$, Yingguang Liang ${ }^{\mathrm{a}}$, Xianmang $\mathrm{Xu}^{\mathrm{c}}$, Guangzhao Xie ${ }^{\mathrm{a}}$, Yaqi Wei ${ }^{\mathrm{a}}$, Hao Sun ${ }^{\mathrm{a}}$, Chao Zhu ${ }^{\mathrm{a}}$, Hongbo Fu, ${ }^{\mathrm{a}}$, and Jianmin Chen ${ }^{\mathrm{a}, \mathrm{b}}$, d*

a Shanghai Key Laboratory of Atmospheric Particle Pollution and Prevention, Department of Environmental Science and Engineering, Institute of Atmospheric Sciences, Fudan University, Shanghai 200433, China

b Shanghai Institute of Eco-Chongming (SIEC), No. 3663 Northern Zhongshan Road, Shanghai 200062, China

${ }^{\mathrm{c}}$ Biological Engineering Technology Innovation Center of Shandong Province, Shandong Academy of Sciences, Heze 274008, China

${ }^{\mathrm{d}}$ Center for Excellence in Regional Atmospheric Environment, Institute of Urban Environment, Chinese Academy of Sciences, Xiamen 361021, China

* Corresponding authors:

(Q. Li) Phone: +86-021-31248901; Email: qli@fudan.edu.cn; (J. Chen) Phone: +86-2131242298; Email: jmchen@fudan.edu.cn

10 pages

1 table

7 figures 


\section{Estimation of desulfurization byproducts in PM emitted at the stack}

The mass concentrations of the most abundant metal elements (i.e., $\mathrm{K}$ and $\mathrm{Fe}$ ) in the sinter FGD inlet (see Figures 4 and S7) can't be increased by the by FGD desulfurizers and their byproducts. The FGD system can remove refractory components via physical interaction, i.e., sweeping mechanisms (wet), collision-agglomeration (semidry), and adsorption (dry). Both water-soluble and -insoluble components in FGD inlet were removed to some extent. In contrast, the desulfurization byproducts/agents (watersoluble or carbonaceous components) lacking Fe and $\mathrm{K}$ can contribute to the suspended particles in the FGD tower and will inevitably supply new components of the PM at the FGD outlets, although dust separators are always subsequently installed. Therefore, when the concentration of newly generated components in the particles is unknown, the proportion of newly generated particles at the outlet of an FGD system can be roughly estimated through the change in concentration of $\mathrm{Fe}$ and $\mathrm{K}$ according to the following equation:

$c_{\text {pri-PM } 2.5, \text { stack-j }}=c_{F e, \text { stack-j }} / \omega_{F e, F G D-i n l e t} \times \omega_{\text {water }- \text { insoluble components, FGD-inlet }}$

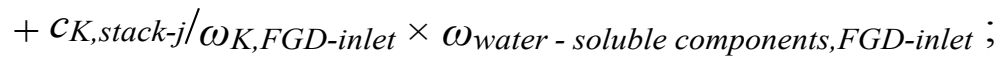

$c_{i \text { in } p r i-P M_{2.5}, \text { stack-j }}=\omega_{i, F G D-i n l e t} \times c_{\text {pri-PM } 2.5, \text { stack-j }} ;$

$c_{i \text { in byproduct-PM } 2.5, \text { stack-j }}=c_{i, \text { stack-j }}-c_{i \text { in } p r i-P M_{2.5}, \text { stack-j }}$;

Cbyproduct $-P M_{2.5,}$ stack $-j=\sum_{i=1, \text { stack-j }}^{n=55}\left(c_{i}\right.$ in byproduct $-P M_{2.5,}$ stack-j $)$,

where $c_{i}$ and $\omega_{i}$ indicate the absolute and relative mass concentration $\left(\%\right.$ and $\mathrm{mg} / \mathrm{Nm}^{3}$, respectively) of chemical component $i$ in $\mathrm{PM}_{2.5}$ at FGD-inlet or stack-j (1-4); $n$ is the number of components; $c_{p r i-P M 2.5}$ and $c_{i}$ in $p r i-P M 2.5$ are the mass concentration of the primary $\mathrm{PM}_{2.5}$ and its chemical component $i$ at stack-j (1-4) without removal by ESP + FGD in the sinter process, respectively, while $c_{\text {byproduct-PM2.5 }}$ and $c_{i \text { in byproduct-PM2.5 }}$ represent the concentrations of newly generated $\mathrm{PM}_{2.5}$ (which is composed of the desulfurization products and/or desulfurizing agents after the FGD system) and its chemical components at stack-j (1-4), respectively. 
Table S1. Information on the parameters of sinter ores, desulfurizer agents and byproducts.

\begin{tabular}{|c|c|c|c|c|c|}
\hline \multirow{2}{*}{ Sampling sites } & \multicolumn{3}{|l|}{ F1 } & \multicolumn{2}{|l|}{$\mathbf{F 2}$} \\
\hline & Stack-1 & Stack-2 & Stack-3 & Stack-4 & Stack-5 \\
\hline Sinter area $\left(\mathrm{m}^{2}\right)$ & 360 & 360 & 600 & 400 & 450 \\
\hline Date of operation & $2008-11-24$ & $2008-8-26$ & 2015-09-14 & 2004-07-01 & 2011-12-01 \\
\hline Production of sinter ore (ton/h) & 454 & 404 & 715 & 504 & 577 \\
\hline Date of FGD installation & $2010-9-20$ & 2016-9-01 & 2015-09-14 & 2009-02-01 & 2011-12-01 \\
\hline Desulfurizer agent & limestone & $\mathrm{NH}_{3} \cdot \mathrm{H}_{2} \mathrm{O}$ & activated coke & slaked lime & slaked lime \\
\hline Desulfurizer agent consumption (ton/h) & 1.25 & 0.18 & 0.49 & 2.23 & 2.67 \\
\hline Denitration agent & - & - & $\mathrm{NH}_{3} \cdot \mathrm{H}_{2} \mathrm{O}$ & - & - \\
\hline Denitration agent consumption (ton/h) & - & - & 0.14 & - & - \\
\hline Water consumption (ton/h) & 56.7 & 45.1 & 25.7 & 38.1 & 43.6 \\
\hline Recycled byproducts & gypsum $\left(\mathrm{CaSO}_{4}\right)$ & $\left(\mathrm{NH}_{4}\right)_{2} \mathrm{SO}_{4}$ & $\mathrm{H}_{2} \mathrm{SO}_{4}$ and coke powder & $\mathrm{CaSO}_{4}$ or $\mathrm{CaSO}_{3}$ & $\mathrm{CaSO}_{4}$ or $\mathrm{CaSO}_{3}$ \\
\hline Byproduct yield (ton/h) & 4.83 & 0.44 & 1.51 & 6.98 & 7.41 \\
\hline
\end{tabular}

54 Note: “_" means no denitrifier is added. 


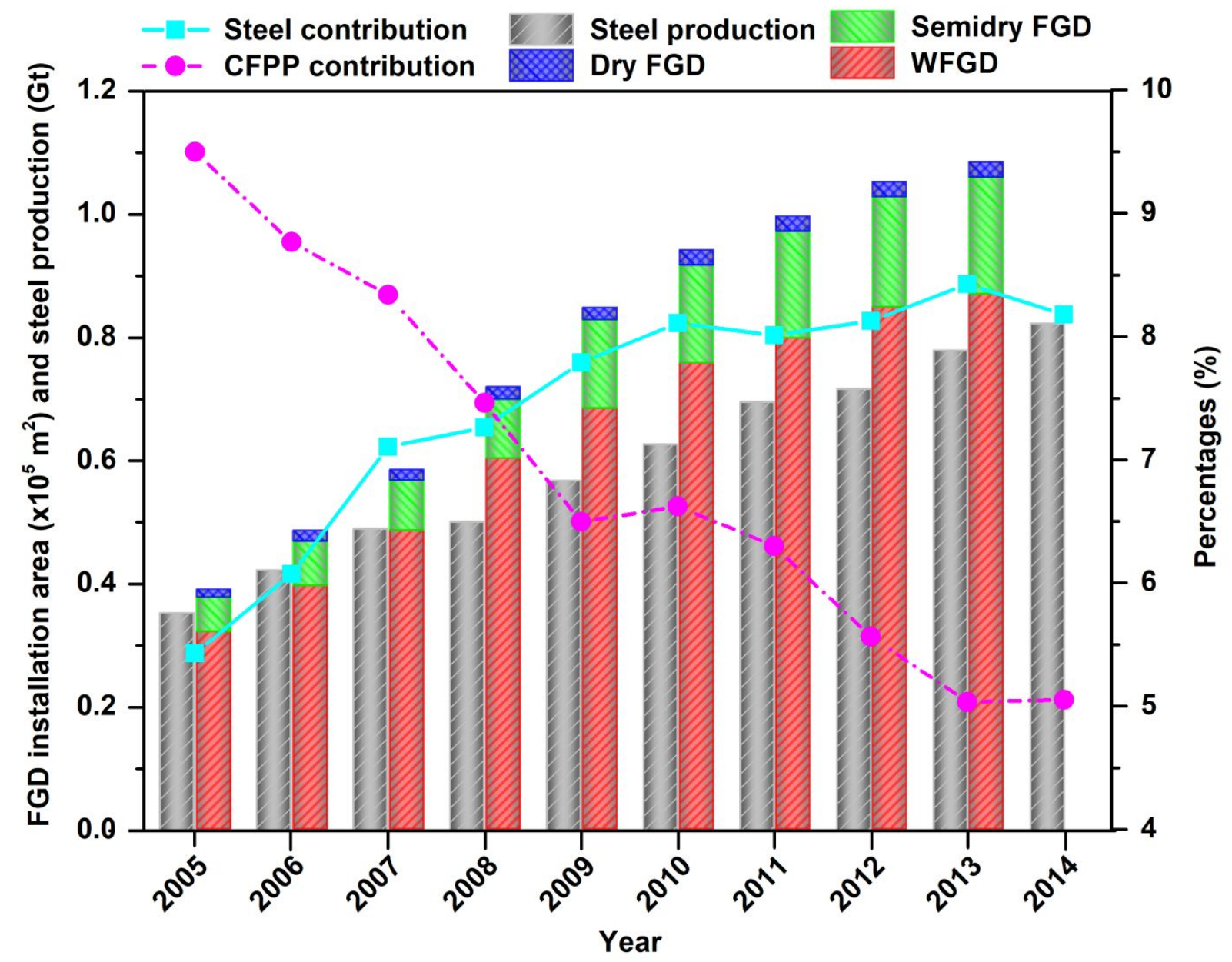

Figure S1. Annual steel production and the relative percentages of primary $\mathrm{PM}_{2.5}$ emissions

57 from steel production and CFPPs in total primary $\mathrm{PM}_{2.5}$ emissions from all anthropogenic sources in mainland China during 2005-2014, as well as installation areas for steel sintering desulfurization facilities during 2005-2013 in mainland China. 

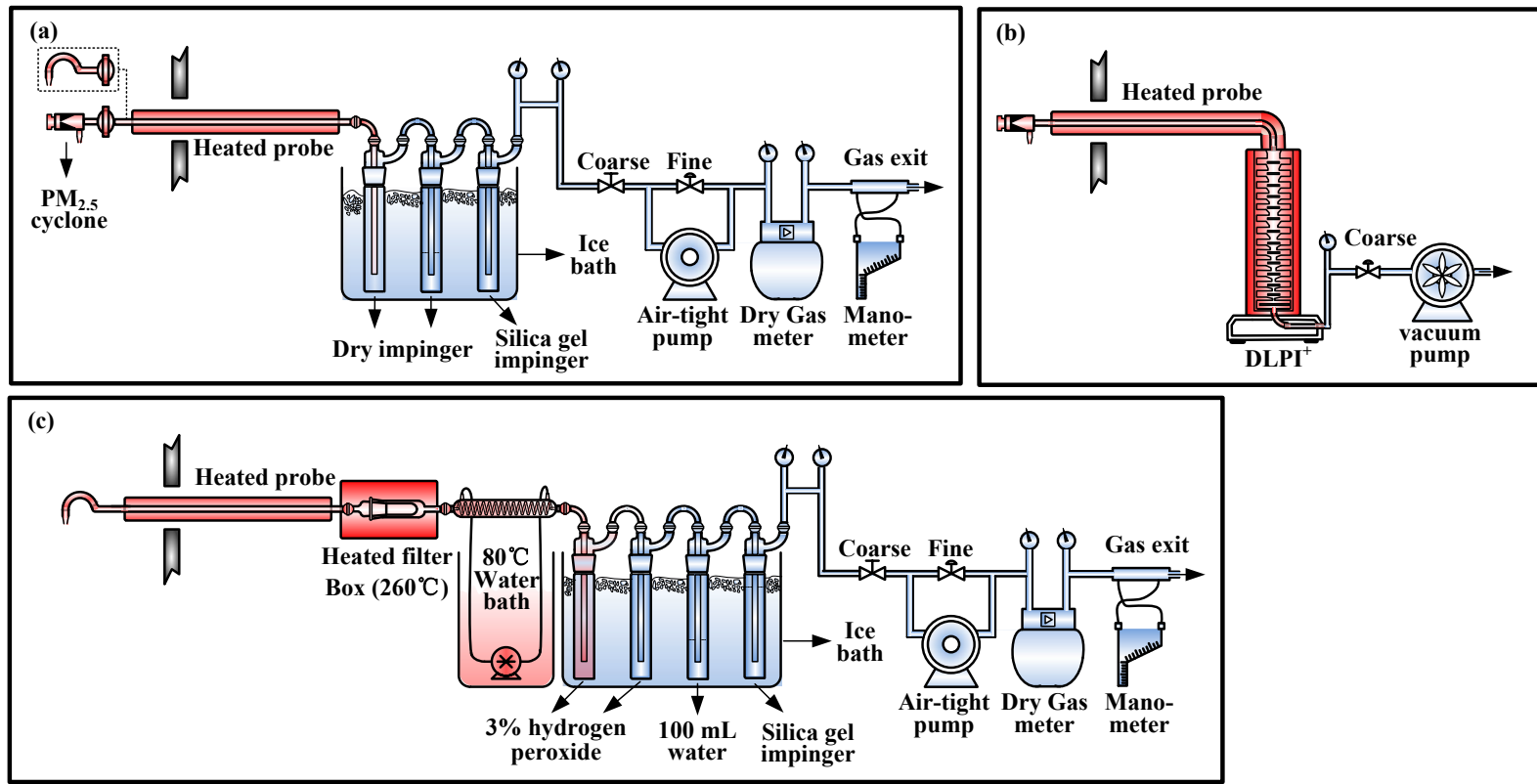

Figure S2. Schematic diagrams of the sampling systems for $\mathrm{TSP} / \mathrm{PM}_{2.5} / \mathrm{NH}_{3} / \mathrm{HCl}$ (a), size-

62 segregated particles (sampled at high temperature using $\mathrm{DLPI}^{+}$) (b), and $\mathrm{SO}_{3}(\mathrm{c})$. 

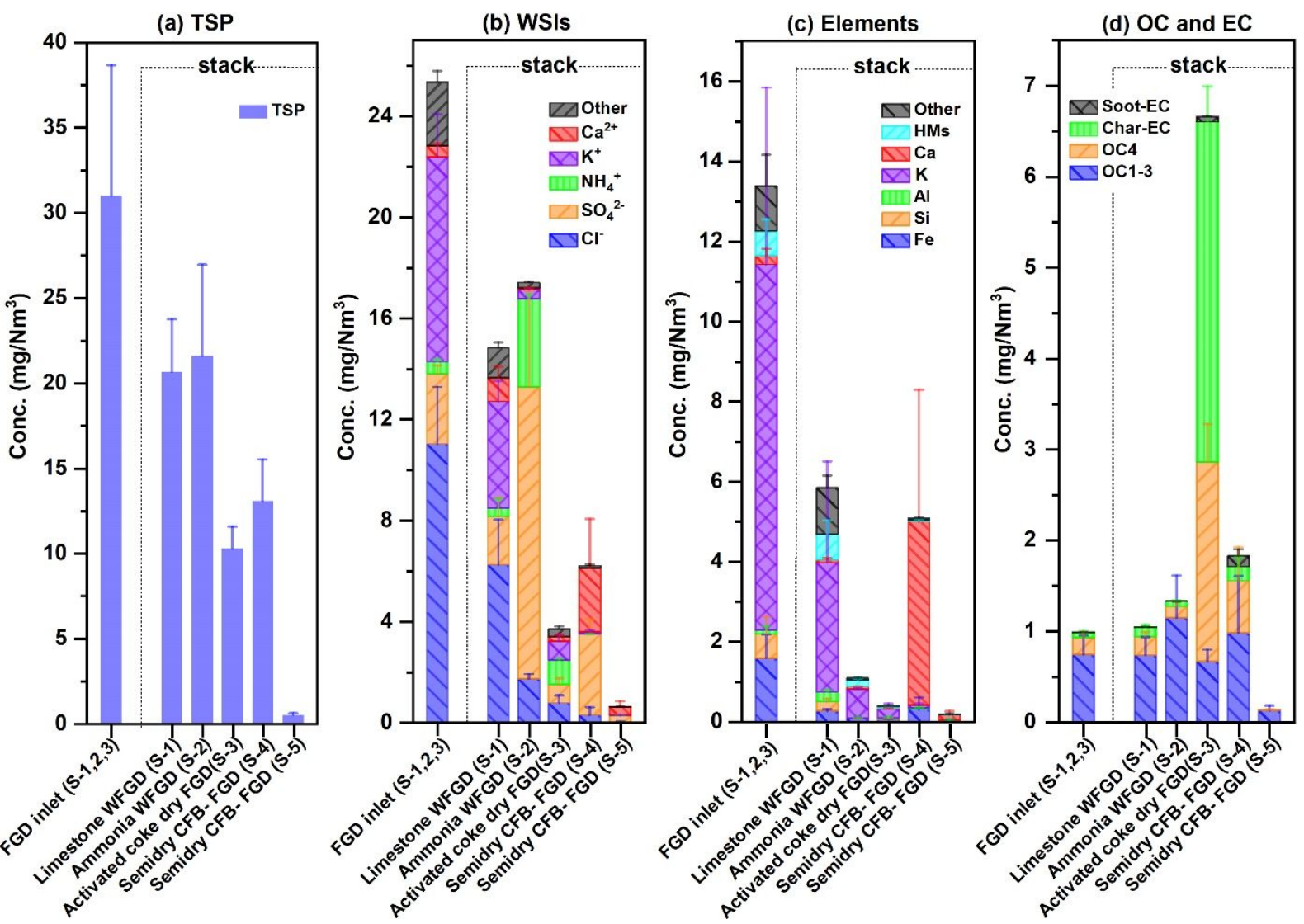

Figure S3. Mass concentrations of (a) TSP and its components: (b) WSIs, (c) elements, and (d) carbonaceous components at FGD inlets/outlets for the five tested sinters. Note: "Other WSIs" includes $\mathrm{F}^{-}, \mathrm{Br}^{-}, \mathrm{NO}_{3}^{-}, \mathrm{Na}^{+}$and $\mathrm{Mg}^{2+}$; "HMs" include $\mathrm{Mn}, \mathrm{Cd}, \mathrm{V}, \mathrm{Cr}, \mathrm{Ni}, \mathrm{Cu}, \mathrm{Zn}, \mathrm{As}$, and $\mathrm{Pb}$; "OC1-3" is the sum of OC1, OC2, and OC3; and "Other elements" includes P, Sn, Sb, Sc, Ti, $\mathrm{Co}, \mathrm{Se}, \mathrm{Br}$, and other trace elements. 


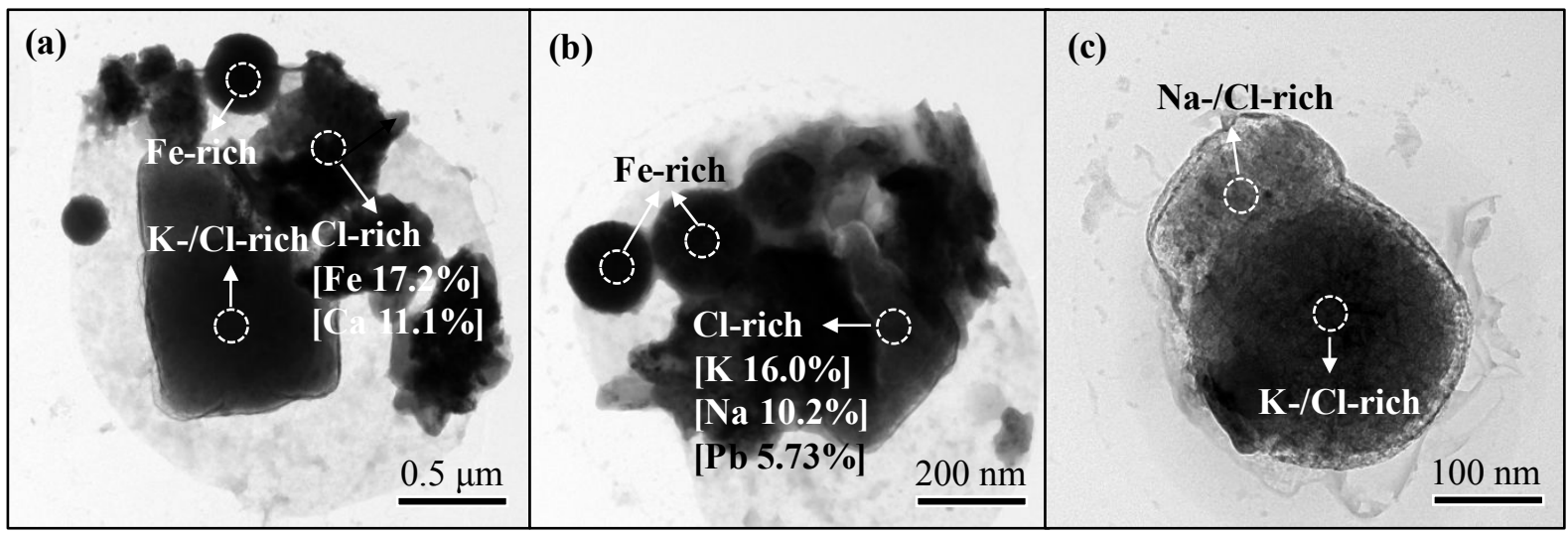

Figure S4. Morphology and elemental composition of sinter particles sampled from the FGD inlet. The results were obtained via TEM coupled with EDS. The dotted white circles denote the EDS analysis areas, while square brackets indicate the mass percent of selected elements. (a) Rectangle-shaped $\mathrm{K}-/ \mathrm{Cl}$-rich particle; an aggregated $\mathrm{Cl}$-rich area mixed with $\mathrm{Fe}$ and $\mathrm{Ca}$, which was frequently observed in the sample and was beam-sensitive under TEM; (b) spherical Fe-rich particles; aggregated $\mathrm{Cl}$-rich area with $\mathrm{K}, \mathrm{Na}$ and minor $\mathrm{Pb}$; and (c) spherical $\mathrm{K}-/ \mathrm{Cl}-$ rich particles. 


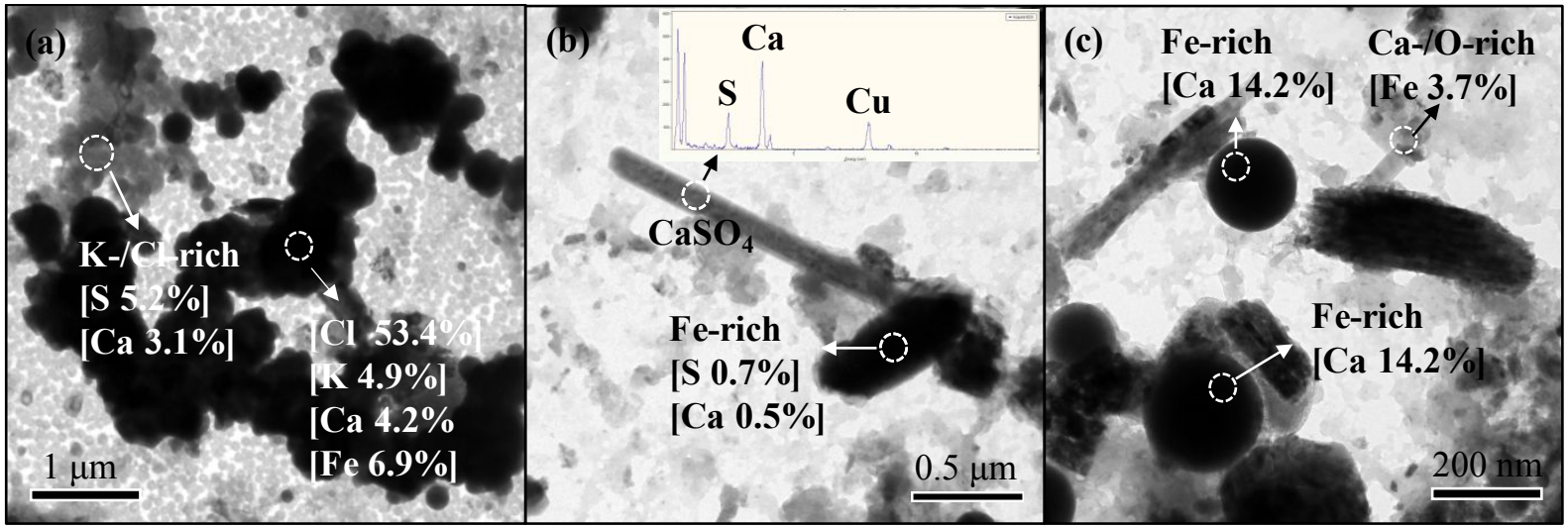

Figure S5. Morphology and elemental composition of sinter particles sampled at the limestone

WFGD outlet. (a) Aggregate of chain-like Cl-rich particles with minor S and $\mathrm{Ca}$; (b) rod-like crystal monomer, $\mathrm{CaSO}_{4}$ (FGD gypsum), and (c) rod-shaped Ca-/O-rich particles, suggesting the coexistence of calcite $\left(\mathrm{CaCO}_{3}\right)$. The EDS results suggest that the PM aggregation is more serious than that of samples collected before FGD treatment and indicate large amounts of ultrafine-mode particles $(<50 \mathrm{~nm})$ resulting from water vapor condensation. 


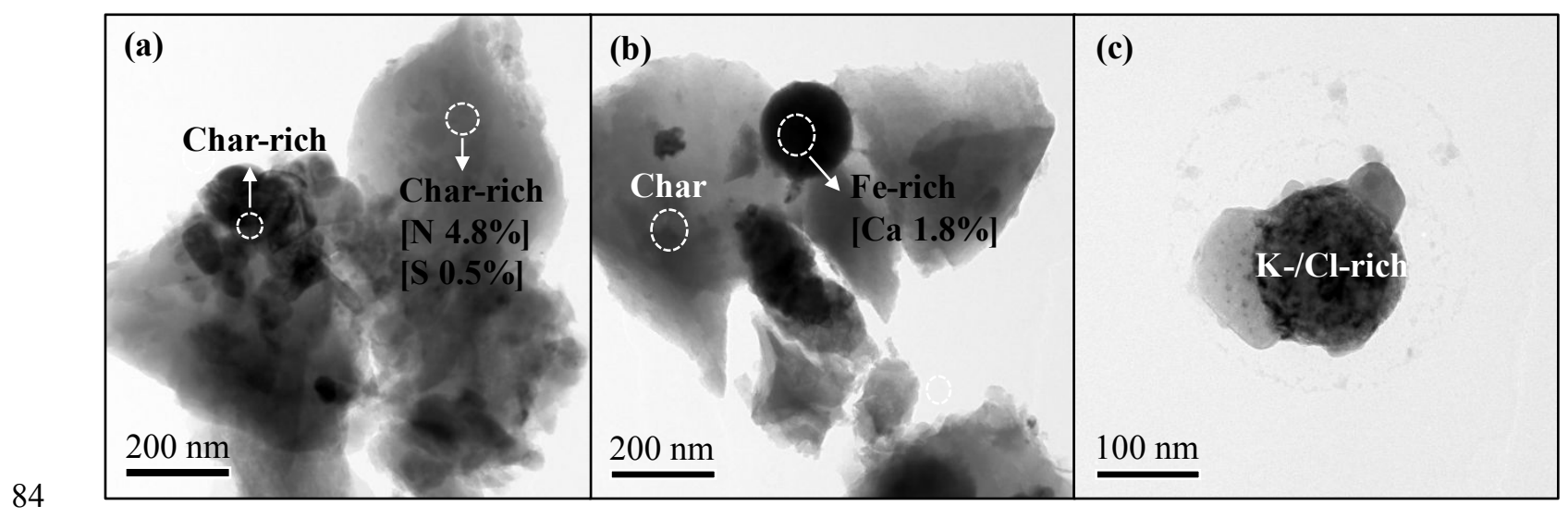

Figure S6. Morphology and elemental composition of sinter particles sampled at the activated coke dry FGD outlet: (a) irregular char-rich particles internally mixed with minor S and $\mathrm{N}$ components, which are abundant in the sample; (b) irregular char-rich particles with dark and spherical Fe-rich inclusions; and (c) spherical K-/Cl-rich particles. 


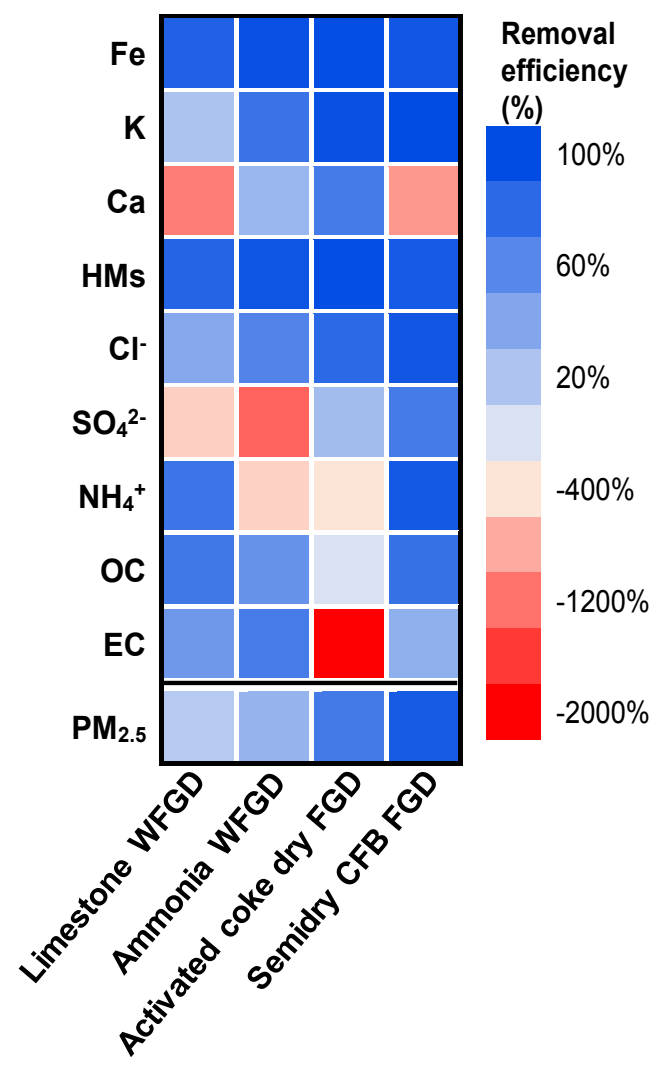

90 Figure S7. Comparison of removal efficiency (\%) of $\mathrm{PM}_{2.5}$ and its major components during

91 different FGD processes; the results for S-5 were not included in this figure owing to the low concentrations and inaccuracy of analysis. 